\title{
The Mapping of Thematic Roles to Grammatical Functions in Mandarin $B A$ Construction Denoting Causation: From the Perspective of Lexical Mapping Theory
}

\author{
Fengqi Li \\ College of Foreign Languages, Southwest University of Political Science and Law, Chongqing, 401120, China
}

\begin{abstract}
NP1 in the position of the subject of the mandarin $B A$ construction denoting causation is usually occupied by patientlike roles and NP2 immediately following $B A$ is usually occupied by agentlike roles. The causative relation between NP1 and NP2, with the former being the Cause, and the latter the Affectee, derives from the word $B A$, which triggers in the lexicon the morpholexical operation of causativization when it unites with the predicate. The operation involves either assignment of causative roles Cause and Affectee to the existent thematic roles or insertion of a new role Cause to the thematic structure, with the prominence of Cause or the thematic role assigned Cause always being over the other roles. Having undergone this morpholexical operation, the thematic structure correctly maps to and generates the grammatical functional structure according to the general principles and conditions stipulated by the Lexical Mapping Theory (LMT). The result of this research shows that even for a construction as unique as the mandarin $B A$ construction denoting causation compared with any other languages, LMT is still well applicable in explaining its role-function mapping.
\end{abstract}

Index Terms-BA construction denoting causation, Lexical Mapping Theory, thematic role, grammatical function, morpholexical operation

\section{INTRODUCTION}

The traditional assumption that the mandarin $B A$ construction semantically denotes disposal (Wang, 1980) has been constantly challenged. Jiang (1997), Shao and Zhao (2005) and Guo (2008), for example, argue that in addition to disposal, the $B A$ construction can also denote causation. Moreover, Guo (2010) identifies a third denotation of the $B A$ construction existing in modern (not contemporary) Chinese: suffering ${ }^{1}$. Sentences (1) through (3) below represent the three types of $B A$ constructions respectively:

(1) 小高把那碗酒喝了。(Disposal)

Xiao Gao ba nawanjiu he le.

Xiao Gao BA that bowl of liquor drank ASP

Xiao Gao has disposed of that bowl of liquor by consuming it.

(2) 那碗酒把小高喝醉了。(Causation)

Nawanjiu ba Xiao Gao he-zui le.

that bowl of liquor BA Xiao Gao drink-drunken ASP

That bowl of liquor has caused Xiao Gao who consumed it to get drunken.

(3) 小高把个媳妇跑了。(Suffering)

Xiao Gao ba ge xifu pao le.

Xiao Gao BA a wife run away ASP

[Unfortunately] Xiao Gao's wife ran away.

The $B A$ construction denoting disposal (hereinafter referred to as Disposal $B A$ ) represents how NP1, the subject of the construction which is usually the proto-agent, has disposed of NP2 immediately following $B A$ which is usually the proto-patient (See Dowty, 1991, p. 572 for the discussion of proto-roles), through an action represented by a VP following $B A+\mathrm{NP} 2$.

The $B A$ construction denoting causation (hereinafter referred to as Causation $B A$ ) describes how $\mathrm{C}$ (the Cause) has caused T (the Target) to have an R (a result) (Zou, 2001, p. 19), where $\mathrm{C}$ is in the position of NP1, the subject, which is sometimes the proto-patient [as in (2)] and sometimes assumes no thematic roles as in (4) below. T corresponds to NP2 which is usually the proto-agent, and the VP after $B A+\mathrm{NP} 2$ denotes both the action and its result.

\footnotetext{
${ }^{1}$ Actually, the $B A$ construction with the denotation of suffering is not only found in modern Chinese, but also in contemporary Chinese, as is shown by (3) below. So I would like to group the $B A$ constructions in contemporary Chinese into three types: those denoting disposal, causation and suffering.
} 
(4) 这活儿把小高累倒了。

Zhe huoer ba Xiao Gao lei-dao le.

This work BA Xiao Gao tire-collapse ASP

This work has caused Xiao Gao to be so tired that he collapsed.

A distinctive feature of the Causation $B A$ in contrast to the Disposal $B A$ is that when the word $B A$ and those preceding it are taken $a^{2}{ }^{2}$, the remaining part is still eligible, with the agent being the subject, and in such a case, $B A$ may be viewed as a delexicalized verb which is semantically equal to SHI (使, meaning “to cause") (Guo, 2008, p. 89). In Sentence (2), for example, after "nawanjiu ba" being taken away, the remaining part "Xiao Gao he-zui le" (Xiao Gao has got drunken) is still an eligible reading, whose subject is the agent. BA serves as the function of $S H I$, or to cause, i.e. it is that bowl of liquor that has caused Xiao Gao to get drunken.

The $B A$ construction denoting suffering (hereinafter referred to as Suffering $B A$ ) means one suffering from damages, misfortune, dissatisfaction, etc., the structure of which can be represented as: (Subject the suffering entity) $+B A+$ Object the theme $+\mathrm{V}+l e$ the aspect (Guo, 2010, p. 50). In this type of construction, NP1 can be either vacant [as in (5)] or be the malficiary, i.e. the recipient of the misfortune [as in (3)], and NP2 is usually the proto-agent. When $B A$ and the words preceding it are taken away, what remains is also an eligible reading, as in (3) where it reads as "Xifu pao le" (The wife has run away). However, NP1 is not the cause of the VP but the recipient of damages or misfortune caused by the VP. This is quite different from the Causation $B A$.

(5) 偏又把风Y头病了。

Pian you ba Feng yatou bing le.

Unfortunately again BA Xifeng girl get sick ASP

Unfortunately Xifeng has got sick.

The thematic structures (or $\theta$-structures) in the semantic level of the three types of $B A$ constructions are diversified, while their grammatical functional structures (or f-structures) in the syntactic level are almost the same: subject + oblique $(B A \mathrm{NP} 2)+$ (retained object). How the latter is generated from the former is a topic worth in-depth exploration. Even within the same type of the $B A$ construction, the $\theta$-structures vary from case to case, which gives rise to complicated process of generation of the f-structures. In this article, I will focus on one type of the $B A$ construction the Causation $B A$ and explore within the framework of Lexical Mapping Theory (LMT) how its $\theta$-structures map to and generate the f-structures.

\title{
II. LEXICAL MAPPING THEORY
}

LMT, initially proposed by Bresnan and Kanerva (1989), is "about the syntactic realization of the arguments of a predicate" (Falk, 2001, p. 101). It is a subordinate theory of Lexical Functional Grammar (LFG) developed in the 1970s. LMT has later been modified by Bresnan (2001), Falk (2001) and Her (2003), among others. In this article, I will base my analysis on Falk (2001, pp. 101-114)'s model (together with my own fine tuning), which distinguishes three hierarchical structures through which the thematic roles assigned by the predicate are mapped to the grammatical functions (GFs):

\author{
thematic structure, or $\theta$-structure \\ $\downarrow$ \\ argument structure, or a-structure \\ $\downarrow$ \\ grammatical functional structure or f-structure \\ Figure 1. Mapping in LMT
}

The mapping between each structure is confined by certain principles and conditions, to which I will offer a brief introduction using the predicate place as an example (see also Li, 2011, 2012 and 2018).

$\begin{array}{lccc}\text { (6) } \text { place } & <\mathrm{ag} & \text { th } & \text { loc }>\ldots \ldots \ldots \ldots \ldots \ldots \ldots \\ \theta \text {-structure } & {[-o]} & {[-r]} & {[-o] \ldots \ldots \ldots \ldots \ldots \ldots \ldots \ldots \ldots} \\ \begin{array}{l}\text { Addition of values } \\ \text { f-structure }\end{array} & {[+o]} & {[+r] \ldots \ldots \ldots \ldots \ldots \ldots \ldots \ldots \ldots \ldots \ldots}\end{array}$

Line 1 shows the $\theta$-structure of place, in which the order of the roles is arranged according to their prominence in the thematic hierarchy, and the left-most role is called the $\hat{\theta}$ (theta hat).

A. Thematic Hierarchy

$\operatorname{ag}($ ent $)>$ ben $($ eficiary $)>\exp ($ eriencer $) /$ go $($ al $)>$ ins $($ trument $)>p(a) t($ ient $) /$ th $($ eme $)>\operatorname{loc}($ ative $)$

In Line 2 is the a-structure of place, where $r$ stands for "thematically restricted", indicating whether a certain GF is restricted by thematic roles, i.e. whether only specific roles, not all roles, correspond to that function, and $o$ is the symbol for "objective", denoting whether the GF is object or not. The values $[ \pm r]$ and $[ \pm o]$ reflect the features of the GFs in the syntactical level, and they per se are arguments which also reflect the prominence of thematic roles in the

\footnotetext{
${ }^{2}$ Guo (2008, p. 89) argues that it is when the word $B A$ (not $B A$ together with the words preceding it) is taken away that the remaining part is eligible, but this may be true only for modern (not contemporary) Chinese, as is shown in such classics as Red Chamber Dream; it may not be true for contemporary Chinese, where only when both $B A$ and the preceding words are taken away can one get eligible readings.
} 
semantic level. Hence it can be said that a-structure is the locus linking both the $\theta$-structure and the f-structure. B below shows how the GFs are decomposed into values of features, and $\mathrm{C}$ are the principles of mapping from the $\theta$-structure to the a-structure.

B. Feature Decomposition of GFs

\begin{tabular}{|c|c|c|}
\hline & {$[-o]$} & {$[+o]$} \\
\hline$[-r]$ & $\mathrm{SUBJ}^{3}$ & $\mathrm{OBJ}$ \\
\hline$[+r]$ & $\mathrm{OBL}_{\theta}{ }^{3}$ & $\mathrm{OBJ}_{\theta}$ \\
\hline
\end{tabular}

C. $\Theta$-structure to A-structure Mapping

a. Patients and themes map to $[-r]$.

b. Secondary patients and themes map to $[+o]$ as a marked option.

c. Non-theme/patient roles map to [-o].

According to $\mathrm{C}-\mathrm{c}$, both the $a g$ and $l o c$ of place is mapped to [-o], and according to $\mathrm{C}-\mathrm{a}$, the $t h$ is mapped to [-r] - this is how the a-structure in Line 2 is generated.

Line 3 shows the process of mapping for the a-structure to the f-structure, which is constrained by three principles and two conditions:

D. A-structure to F-structure Mapping

a. SUBJ mapping 1: A [-o] which is ê maps to SUBJ.

b. SUBJ mapping 2: [-r] may map to SUBJ.

c. NonSUBJ mapping: Add positive values of features where possible.

E. Well-formedness of A-structure to F-structure Mapping

a. Function-argument biuniqueness (FAB): Each a-structure role corresponds to a unique f-structure function, and each f-structure function corresponds to a unique a-structure role.

b. The subject condition: Every predicator must have a subject.

Based on D-a, the first argument of place [-o], which corresponds to the $\hat{\theta}$ - agent in the $\theta$-structure, is directly mapped to the SUBJ in the f-structure. The second argument [-r] can also be mapped to SUBJ according to D-b, but this would violate E-a because, if so, SUBJ would correspond to two arguments. At this time, D-c stands out and adds the positive value $[+o]$ to $[-r]$ (it is $[+o]$, not $[+r]$, that is added because the latter would contradict the existing value $[-r]$ ). Similarly, the positive value $[+r]$ is added to the third argument $[-o]$. Finally, both the second and third arguments are respectively mapped to $\mathrm{OBJ}$ and $\mathrm{OBL}_{\mathrm{loc}}$ according to $\mathrm{B}$.

The afore-mentioned principles and conditions are supposed to be universal across languages, but they may not be applicable directly to individual languages for the sake of parametric variation. Certain morpholexical operations, including deletion, insertion or change of roles (or sometimes of arguments ${ }^{4}$ ), are needed to modify the $\theta$-structure (or the a-structure) within the lexicon before the universal principles and conditions are applicable.

\section{III. $\Theta$-STRUCTURES OF CAUSATION $B A$}

The VP in the Causation $B A$ is usually a verb compound: it can be a resultative verb compound (RVC), like he-zui in (2) and lei-dao in (4), or a V-DE construction, "a complex stative construction" (Li, 2015, p. 2), like jide tuantuanzhuan and chide zhi xiang tu in (7) and (8).

(7) 小高把他妈急得团团转。

Xiao Gao ba tama ji-de- tuantuanzhuan.

Xiao Gao BA his mum worry-DE pace around

Xiao Gao worried his mum so much that she paced around (like a cat on hot bricks).

(8) 这碗饭把小高吃得直想吐。

Zhewanfan ba Xiao Gao chi-de- zhi- xiang- tu.

This bowl of rice BA Xiao Gao eat-DE almost want vomit

This bowl of rice that Xiao Gao was eating almost caused him to vomit.

The Head of the compound (which is the first verb) in the Causation $B A$ can be a one-valency verb like lei and $j i$, or a two-valency verb like chi and he. Most of the compounds can not be followed by a retained object, but they can if they are composed of the Head and cheng le (become ASP):

(9) 那条阴沟把这好好的孩子摔成了个残废。（Zou, 2001, p.18）

Natiao yingou ba zhe haohaode haizi shuai-cheng le ge caifei.

That ditch BA this able-bodied child tumble-become ASP a cripple

${ }^{3} \mathrm{OBL}=$ oblique case, as "on his head" in "He placed a rabbit on his head". It is a grammatical function whose role (usually thematic role) is explicitly marked, either by a preposition (as in English) or a semantic Case. The subscript " $\theta$ " indicates it is restricted to certain thematic roles. In the case of place, only the role of loc can fill the position, so this grammatical function is represented as $\mathrm{OBL}_{\text {loc. }} \mathrm{OBJ}_{\theta}$ refers to the secondary object in some languages which is characteristically restricted to a single thematic role or a small set of thematic roles.

${ }^{4}$ Traditional LMT did not mention operation of arguments, nor change of roles, but in some mandarin expressions like $B A$ constructions and resultative verb compounds, morpholexical operations in these aspects are quite necessary to ensure correct mapping from the $\theta$-structure to the f-structure. 
That ditch into which the child was tumbled has turned him from an able-bodied person to a cripple.

(10) 那副药把小高吃成了个俊子。

Nafuyao ba Xiao Gao chi-cheng le ge shazi.

That medicine BA Xiao Gao eat-become ASP a fool

That medicine Xiao Gao took has caused him to become a fool.

Differences in the valency of the verbs and the presentation (or lack) of retained objects naturally lead to different $\theta$-structures:

\begin{tabular}{|c|c|c|}
\hline 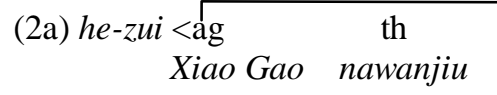 & $\begin{array}{l}\langle\exp >> \\
\text { Xiao Gao }\end{array}$ & \\
\hline $\begin{array}{rr}\text { (4a) lei-dao }<\text { exp } & <\mathrm{th}>> \\
\text { Xiao Gao } & \text { Xiao Gao }\end{array}$ & & \\
\hline $\begin{array}{r}\text { (7a) ji-de-tuantuanzhuan }<\underset{\exp }{\text { tama }}\end{array}$ & $\begin{array}{l}\langle\mathrm{th}\rangle> \\
\text { tama }\end{array}$ & \\
\hline $\begin{aligned} & \text { (8a) chi-de-zhi-xiang-tu }<\mathrm{ag} \\
& \text { Xiao Gao }\end{aligned}$ & $\begin{array}{c}\mathrm{pt} \\
\text { zhewanfan }\end{array}$ & $\begin{array}{r}<\exp >> \\
\text { Xiao Gao }\end{array}$ \\
\hline 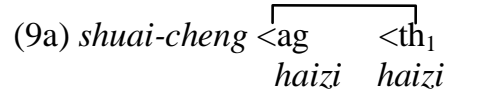 & $\begin{array}{l}\mathrm{th}_{2} \gg> \\
\text { canfei }\end{array}$ & \\
\hline $\begin{array}{rc}\text { (10a) chi-cheng }<\text { ag } & \mathrm{pt} \\
\text { Xiao Gao } & \text { nafuyao }\end{array}$ & $\begin{array}{l}<\mathrm{th}_{1} \\
\text { Xiao Gao }\end{array}$ & $\begin{array}{l}\operatorname{th}_{2}>> \\
\text { shazi }\end{array}$ \\
\hline
\end{tabular}

The illustrations, where the broken line means one entity bearing two roles simultaneously, the outer pointed brackets represent the $\theta$-structure of the Head and the inner ones indicate the $\theta$-structure of the other verb following the Head, provide us with a complicated picture of the $\theta$-structures of the Causation $B A$.

What is noticeable is that one entity may bear two thematic roles in this type of constructions, like "Xiao Gao" in (2a) who bears the role of agent assigned by he and simultaneously the role of experiencer assigned by zui. These two roles constitute one "composite role", represented as ag-exp (see Her, 2004 and Li, 2011 for more discussion about composite roles).

It is also noticeable that some VPs like lei-dao, ji-de-tuantuanzhuan and shuai-cheng may assign an additional role when appearing in the $B A$ construction, a situation which can not possibly occur in a more "normal" reading where the proto-agent is at its usual position of the subject:

(4b) 小高累倒了。

Xiao Gao lei-dao le.

Xiao Gao tire-collapse ASP

Xiao Gao has got so tired that he collapsed.

(7b) 他妈急得团团转。
Tama ji-de-
tuantuanzhuan.

His mum worry-DE- pace around

His mum was worried so much that she paced around (like a cat on hot bricks).

(9b) 孩子摔成了个残废。

Haizi shuai-cheng le ge caifei.

Child tumble-become ASP a cripple

The child was tumbled into a cripple.

In these "normal" readings, only one or two roles are assigned (the composite role is counted as one role), but in their corresponding BA constructions (4), (7) and (9), an additional role is introduced, borne respectively by zhehuoer, Xiao Gao and natiao yingou.

How are such complicated $\theta$-structures of the Causation $B A$ mapped to the f-structures? This is the question to be addressed in the following sections. Since the $\theta$-structures of both RVC and V-DE constructions are similar to each other and the paths of mapping from the $\theta$-structures to the f-structures are also similar, I will only focus on the former in the following discussion.

\section{F-STRUCTURE OF CAUSATION $B A$}

LFG divides GFs into two types (Dalrymple, 2001):

Governable: SUBJect, OBJect, OBJect ${ }_{\theta}$, COMPlement, XCOMPlement, OBLique $_{\theta}$ 
Non-governable: ADJunct, XADJunct ${ }^{5}$

Studies in LMT frequently focuses on the four major governable functions: SUBJ, OBJ, $\mathrm{OBJ}_{\theta}$ and $\mathrm{OBL}_{\theta}$. There is no exception for this study. What is out of question is that NP1 in the Causation $B A$ corresponds to SUBJ, but what remains a problem is the GF NP2 corresponds to. This actually is determined by the syntactic properties and semantic functions of the very word $B A$. It has been labeled as a verb, co-verb, light verb or preposition respectively by different researchers (Zhang \& Bai, 2013, p. 139). But at present a consensus seems to have been arrived at in the field of generative grammar, which views $B A$ as a light verb. Huang, $\mathrm{Li}$ and $\mathrm{Li}$ (2009), for example, claims in The Syntax of Chinese that " $B A$ is an explicit light verb which does not assign thematic roles and has a VP as its complement; the NP following $B A$ is the external OBJ of the VP, which is semantically related to its internal OBJ" (As cited in $\mathrm{Hu}, 2011$, p. 208).

As for the semantic functions of $B A$, an obvious one is to express the meaning of causation. What is equally important is the function of introducing and marking a role of the VP (since it does not assign any roles) represented by NP2. In this sense, NP2 can be said to correspond to the OBL, a GF that is "associated with particular semantic roles and marked to indicate their function overtly" (Dalrymple, 2001, p. 26). In the $B A$ construction, only specific roles can appear in the position of NP2, and what is more, they are overtly marked by $B A$. This conforms to the semantic function of an OBL.

Nevertheless, it is not without controversy concerning the category label of $B A$. As has been pointed out by Kit (1998, p. 499), since Zhang (1956), researchers of Chinese linguistics have tended to see $B A$ as a simple preposition. Yang (2014, p. 418) also implicitly take $B A$ as a preposition in the discussion of the thematic roles of the $B A$ construction. Wen and Cheng (2007, p. 112), on the other hand, explicitly exclude $B A$ from the category of light verbs. However, the controversy about $B A$ 's syntactic properties does not alter its semantic function as a marker of specific roles of the VP. Hence, the fact of NP2 corresponding to OBL does not change with the change of the category label of $B A$.

In addition to NP1 and NP2, NP3 also exists in some cases when the VP has its own retained object. In such cases, of course, NP3 corresponds to OBJ.

Take again (2), (4), (9) and (10). Their f-structures are represented as:

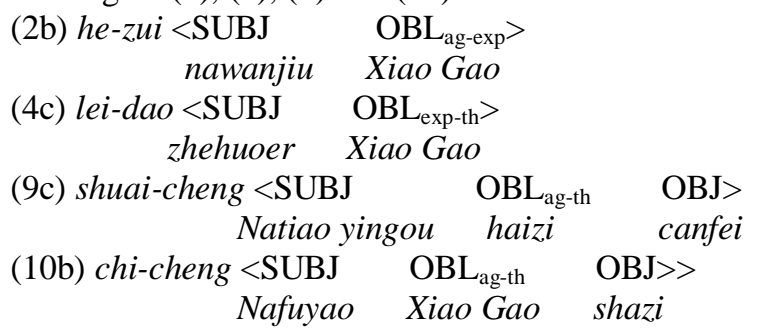

It can be seen that diversified as the $\theta$-structures of the Causation $B A$ are, its f-structures are quite similar (SUBJ, OBL, with or without OBJ). Then how does mapping from the former to the latter occur? Can LMT correctly predict the mapping since the Causation $B A$ is an alien construction compared with the majority of other patterns both in Chinese and other languages including English on which LMT was developed? These questions will be answered in the next section.

\section{MAPPING OF $\Theta$-STRUCTURE TO F-STRUCTURE}

For the Causation $B A$, the first problem concerning mapping is that of the composite roles, which means two roles are simultaneously mapped to one GF, which would violate FAB (E-a). In (2a), for instance, the two constituent roles $a g$ and $\exp$ of the composite role ag-exp are mapped respectively to $[-o]$ and [-o], which in turn are simultaneously mapped to one single GF, namely, OBL [as is shown in (2c)]. To tackle this problem, Her (2004) and Li (2011) propose a morpholexical operation rule of "role suppression", which means through the operation undergoing in the lexicon, the role assigned by the Head of the VP figures prominently and suppresses the other role, with only the former being mapped to the a-structure and further to the f-structure ( $\mathrm{Li}, 2011)$. Under this rule, the mapping of (2c) is modified [as is shown in (2d) where $\varnothing$ indicates role suppression].
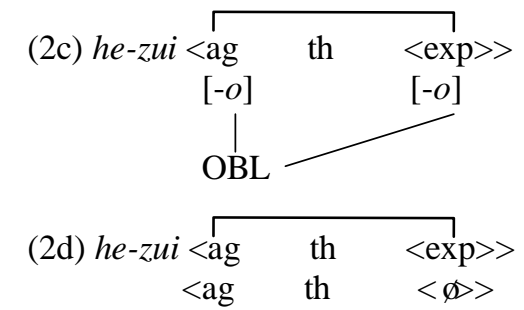

\footnotetext{
${ }^{5}$ Governable and non-governable mean whether the grammatical function can be governed by the predicate or not.
} 


\author{
$[-o]$ \\ OBL
}

Composite roles are not unique to the Causation $B A$ or the other types of $B A$ constructions; they are ubiquitous in Chinese where verb compounds exist in large numbers. Whenever there is a verb compound, there is the possibility of the existence of composite roles because each of the constituent verbs will assign its own roles, some of which may be co-borne by one single entity. So the solution to the mapping problem of composite roles is just a tiny part of the story; more is needed to tackle the mapping problem of the whole construction.

Since the complexity and diversity of the $\theta$-structures of the VP in the Causation $B A$ are largely attributed to the Heads with different valencies, as can be seen from the discussion in Section 3, and since different $\theta$-structures will naturally lead to different mapping processes, in this section I will explore the $\theta$-structure to f-structure mapping by dividing the Causation $B A$ constructions into two groups: those with a two-valency Head in the VP and those with a one-valency Head in the VP.

\title{
A. Mapping When the Head Is of Two Valencies
}

If the Head of the VP in the Causation $B A$ is a two-valency verb, it will assign two roles, one of which may form a composite role with one assigned by the other verb in the compound. Take (2) again as an example:

$\begin{array}{llll}\text { (2e) } h e-z u i & <\mathrm{ag} & \text { th } & \langle\mathrm{exp}\rangle\rangle \\ \text { Role suppression } & <\mathrm{ag} & \text { th } & \langle\phi\rangle\rangle \\ \text { A-structure } & {[-o]} & {[-r]} & \\ \text { Addition of values } & & {[+o]} & \\ \text { F-structure } & \text { SUBJ? } & \text { OBJ? } & \\ & \text { Xiao Gao } & \text { nawanjiu } & \end{array}$

Following the standard path of mapping regulated by the LMT principles and conditions, the composite role ag-exp is mapped to SUBJ, and the role th to OBJ. But what we get is a reading without BA: Xiao Gao he-zui le nawanjiu (Xiao Gao consumed that bowl of liquor and got drunken), instead of the original $B A$ construction. This means that parametric variation exists with the mapping of this particular construction. We can assume that, when $B A$ unites with the VP in the lexicon, some morpholexical operation has to function to modify the $\theta$-structure or a-structure before the LMT principles and conditions can function well to ensure the correct mapping. In other words, it is the introduction of $B A$ that triggers the operation that "rectifies" the unconventional linguistic parameter and brings it back to the "right path."

Then what is the morpholexical operation $B A$ triggers? A comparison of the reading without $B A$ and the one with $B A$ [(2)] may reveal that the former is an objective report of the fact, while the latter puts stress on causation: It is exactly that bowl of liquor that has caused Xiao Gao to get drunken. This is why we call this type of $B A$ construction as Causation $B A$, and it is dependent on $B A$ that the meaning of causation is known to the readers. Hence, we can assume that the morpholexical operation of causativization is triggered when $B A$ unites with he-zui in the lexicon. Causativization assigns two causative roles, namely Cause and Affectee, to the existing roles, bringing about the changes of their hierarchical relation, i.e. the prominence in the $\theta$-structure, so that they can be correctly mapped to the f-structure ${ }^{6}$. The lexical rule that governs this operation can be tentatively expressed as:

F. Causativization of the Causation BA

When $B A$ denoting causation unites with a verb compound, the Cause $(C)$ is assigned to the proto-patient of the Head and Affectee (A) to its proto-agent; the role assigned C has prominence over any other roles in the $\theta$-structure.

In this rule, it is the roles of the Head, not those of the other verb, that are assigned causative roles. This is because the latter have been suppressed in the morpholexical operation of role suppression which functions prior to causativization. The assignment of causative roles stipulated in the rule is based on the observation that the proto-agent of the Head (borne by NP2) is always acted upon by the Cause, while the proto-patient (borne by NP1) is always the Cause that acts upon the proto-agent.

Now apply this rule to the mapping of (2) and we will see the right outcome:

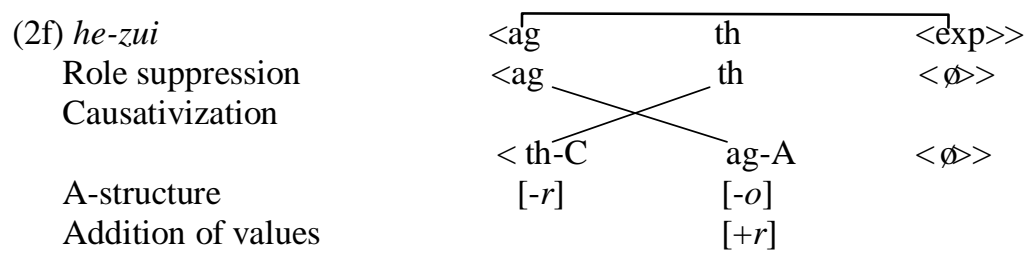

\footnotetext{
${ }^{6}$ Causativization is proposed by Li (1995) in the discussion of the mapping between thematic roles and syntactic arguments of mandarin RVC within the framework of GB. The core concepts are: thematic roles and causative roles are simultaneously assigned to the arguments when causative relation exists between the constituent elements of the verb compound; similar to thematic roles, there is also hierarchical relation between causative roles, with Cause being more prominent than Affectee; causative hierarchy has priority over thematic hierarchy whenever there is a conflict. In this article I borrow the concept of causativization to discuss the role-function mapping of the Causation $B A$ within the framework of LMT.
} 


\section{F-structure $\quad$ SUBJ $\quad \mathrm{OBL}_{\mathrm{ag}-\exp }$ \\ nawanjiu Xiao Gao}

First, exp is suppressed due to the rule of role suppression; then, Rule $\mathrm{F}$ is activated to assign $\mathrm{A}$ and $\mathrm{C}$ respectively to $a g$ and $t h$, and this inverts their hierarchical relation, with th being more prominent than $a g$ and becoming the $\hat{\theta}$. Till now, the $\theta$-structure has been modified in the lexicon, and what follows is the functioning of the LMT principles and conditions which will regulate the follow-up mapping: One, th is mapped to [-r] according to $\mathrm{C}-\mathrm{a}$, and $a g$ to [-o] according to C-c; two, [-r] may be mapped to SUBJ according to D-b and this is strengthened because of its correspondence to the $\hat{\theta}$; three, $[-o]$ is added a positive value $[+r]$ according to $\mathrm{D}-\mathrm{c}$ and is mapped to OBJ according to B. The result we get is exactly the f-structure as is shown in $(2 b)$, which manifests that Rule $F$ is legitimate in modifying the $\theta$-structure of the VP so that it can be mapped to the f-structure along the right path under the guidance of the LMT principles and conditions.

To test the applicability of Rule F, I will examine a more complicated case [see (10)]: the Causation $B A$ with the VP having a retained object where the Head is still of two valencies.

$\begin{array}{lcccc}\text { (10c) chi-cheng } & <\mathrm{ag} & \mathrm{pt} & <\mathrm{th}_{1} & \mathrm{th}_{2}>> \\ \begin{array}{l}\text { Role suppression } \\ \text { Causativization }\end{array} & <\mathrm{ag} & \mathrm{pt} & <\emptyset & \mathrm{th}_{2}>> \\ & <\mathrm{pt}-\mathrm{C} & \mathrm{ag}-\mathrm{A} & <\emptyset & \mathrm{th}_{2}>> \\ \text { A-structure } & {[-r]} & {[-o]} & & {[-r]} \\ \text { Addition of values } & & {[+r]} & {[+o]} \\ \text { F-structure } & \text { SUBJ } & \mathrm{OBL}_{\mathrm{ag}-\mathrm{th}} & \mathrm{OBJ} \\ & \text { nafuyao } & \text { Xiao Gao } & \text { shazi }\end{array}$

Similar to the mapping in (2f), pt and $a g$ are correctly mapped to SUBJ and $\mathrm{OBL}_{\theta}$ when $B A$ triggers the morpholexical operation of causativization. $\mathrm{Th}_{2}$, which corresponds to NP3 the retained object, not influenced by causativization since it is not the role assigned by the Head, is also correctly mapped to OBJ according to the LMT principles and conditions. It shows that, complicated as the $\theta$-structure of the Causation $B A$ is, Rule $\mathrm{F}$ together with the LMT principles and conditions can guarantee correct role-function mapping.

\section{B. Mapping When the Head Is of One Valency}

Different from the verb compounds with a two-valency Head, those with a one-valency Head will usually assign new thematic roles as long as they are integrated into the Causation $B A$ (see Section III). This is also assumably attributed to the semantic function of $B A$, which triggers a kind of morpholexical operation that adds a new thematic role for the compound in the lexicon when it unites with the latter. Take (4) as an example. The VP lei-dao only assigns one composite role exp-th (4a) before $B A$ joins it, but an additional role borne by zhe huoer appears after $B A$ joins it. This role can not be $a g$ for it does not initiate the action of lei tire, nor can it be exp for it is not zhe huoer but Xiao Gao who felt tired. It can not be any other agent-like roles, either. As a matter of fact, instead of being a thematic role, it is purely a causative role, namely the Cause, that brings about the consequence of Xiao Gao lei (Xiao Gao got tired). Here what $B A$ triggers is not the assignment of causative roles to the existent thematic roles but the insertion of $\mathrm{C}$ to the original $\theta$-structure. Likewise, we can assume that $\mathrm{C}$ has the prominence over any other roles, i.e. it being the $\hat{\theta}$. We also assume that it is mapped to $[-o]$ since the NP representing $\mathrm{C}$ generally will not be the OBJ. Then we get another lexical rule:

G. Cause insertion of the Causation $B A$ :

When $B A$ denoting causation unites with a verb compound, the Cause is inserted to the latter's $\theta$-structure, and is kept prominent over the other roles and mapped to [-o].

According to this rule, the mapping of (4) can be represented as:

(4d) lei-dao

Role suppression

Insertion

A-structure

Addition of values

F-structure

$\begin{array}{ll}<\exp & \langle\mathrm{th}\rangle\rangle \\ <\exp & \langle\emptyset\rangle\rangle \\ \exp & \langle\emptyset\rangle\rangle \\ {[-o]} & \\ {[+r]} & \\ \text { OBL }_{\exp } & \\ \text { Xiao Gao } & \text { Xiao Gao }\end{array}$

$\mathrm{C}$, after being inserted, becomes the $\hat{\theta}$ and is mapped to [-o] and further to SUBJ according to D-a. Exp is mapped to $\mathrm{OBL}_{\theta}$ according to C-c and D-c. So the mapping is successfully accomplished.

Rule $\mathrm{G}$ is also applicable to the Causation $B A$ with a retained OBJ. Take (9) as an example:

(9d) shuai-cheng

Role suppression

Insertion

A-structure

Addition of values

$\begin{array}{lll}r \text { ag } & <\text { th }_{1} & \text { th }_{2}>> \\ <\mathrm{ag} & <\emptyset & \mathrm{th}_{2}>> \\ \mathrm{ag} & <\emptyset & \mathrm{th}_{2}>> \\ {[-o]} & & {[-r]} \\ {[+r]} & & {[+o]}\end{array}$




$$
\begin{array}{llll}
\text { F-structure } & \text { SUBJ } & \text { OBL }_{\text {ag-th1 }} & \text { OBJ } \\
& \text { natiao yingou } & \text { haizi } & \text { canfei }
\end{array}
$$

As a matter of fact, Rule G, like Rule F, is a kind of causativization by nature since it changes a reading without causative meaning (haizi shuai-cheng le ge canfei The child was tumbled into a cripple) into one with causative meaning [(10)] by inserting the causative role Cause (represented by natiao yingou). Besides, in the lexicon, BA is the identical word with the one in the previously discussed case, i.e. the Causation $B A$ with a verb compound whose Head is a two-valency verb, which means that it is redundant or even contradictory to govern causativization triggered by the same $B A$ with two different rules. Therefore, it is quite necessary to integrate $\mathrm{F}$ and $\mathrm{G}$ into one single rule to govern the two kinds of causativization which are seemingly different but in essence are the same. Just two steps are needed to accomplish the integration: First, naming the two rules with one term: causativization, and second, clarifying when to insert and when to assign the causative roles. Then the integrated rule can be represented as:

H. Causativization of the Causation $B A$ :

When $B A$ denoting causation unites with a verb compound, it either inserts $C$ (the Cause) to the latter's $\theta$-structure and maps it to [-o] (when the Head is a one-valency verb), or assign $\mathrm{C}$ to the proto-patient of the Head and $\mathrm{A}$ (the Affectee) to its proto-agent (when the head is a two-valency verb); $\mathrm{C}$ or the role assigned $\mathrm{C}$ has prominence over any other roles in the $\theta$-structure.

This rule covers both cases of the Causation $B A$ which have different $\theta$-structures and gets $B A$ to automatically determine whether to insert or assign causative roles based on the valency of the Head so that redundancy and randomness are avoided.

\section{CONCLUSION}

The VPs that can enter the Causation $B A$ are usually verb compounds like RVCs and V-DE constructions, the Head of which can be of one valency or two valencies. When the very word $B A$ denoting causation unites with the VPs in the lexicon, it will trigger the morpholexical operation of causativization which either inserts the causative role Cause to the $\theta$-structure of the Head when it is of one valency or assigns the two causative roles Cause and Affectee to its existent thematic roles when it is of two valencies. The inserted Cause will be mapped to [-o]; the Cause or the role assigned Cause possesses prominence higher than any other roles in the $\theta$-structure. The $\theta$-structures of the Causation $B A$, having undergone this morpholexical operation, are mapped successfully to the f-structures following the path stipulated by the LMT principles and conditions.

The result of this research provides adequate evidence for the explanatory power of LMT whose principles and conditions that are hypothesized to be universal across languages can ensure the correct mapping of $\theta$-structures to f-structures of the Causation $B A$ after morpholexical operation that is of language-specific parametric variation, no matter how diversified and complicated the construction's $\theta$-structures are and how alien its f-structure may seem to be, compared with other languages like English.

As has been mentioned, there are three types of $B A$ constructions in contemporary Chinese. Even though they are gathered under the same umbrella of " $B A$ constructions", the word $B A$ in each type has different semantic functions, which means that the morpholexical operation $B A$ triggers may be different and accordingly the $\theta$-structure to f-structure mapping may also be different. It is not likely that one lexical rule be applied to govern the morpholexical operations of all types of $B A$ constructions. It may be legitimate to see $B A$ in each type as a different word stored in the lexicon which functions differently in its domain. Therefore, the three types of $B A$ constructions need to be investigated separately in order to explore the different ways of realization of the $\theta$-structure in the surface f-structure. I have discussed the Disposal $B A$ elsewhere ( $\mathrm{Li}, 2018)$ and the Causation $B A$ in this article; further research is needed to explore the Suffering $B A$.

\section{REFERENCES}

[1] Bresnan, J. \& J. Kanerva. (1989). Locative inversion in Chicheŵa: A case study of factorization in grammar. Linguistic Inquiry $1,1-50$.

[2] Bresnan, J. (2001). Lexical-functional syntax. Malden: Blackwell Publishers Inc.

[3] Dalrymple, M. (2001). Lexical functional grammar. San Diego: Academic Press.

[4] Dowty, D. (1991). Thematic proto-roles and argument selection. Language 67.3, 547-619.

[5] Falk, Y. N. (2001). Lexical-functional grammar: An introduction to parallel constraint-based syntax. Stanford: CSLI Publications.

[6] Guo, H. Y. (2010). A special BA construction in modern Chinese: BA construction denoting suffering. Linguistic Research 2 , 50-54.

[7] Guo, Y. N. (2008). Syntactic, semantic and pragmatical analysis of BA construction denoting causation. Chinese Linguistics 1, 89-94.

[8] Her, O. S. (2003). Chinese inversion constructions within a simplified LMT. Journal of Chinese Linguistics Monograph Series 19, 1-31.

[9] Her, O. S. (2004). Argument-function linking in resultatives. Concentric: Studies in Linguistics 30.2, 1-34.

[10] Hu, B. (2011). Introduction to and comments on The Syntax of Chinese. Modern Foreign Languages 34.2, 208-210.

[11] Huang, C. T. J., Li, A. \& Y. Li. (2009). The syntax of Chinese. Cambridge: Cambridge University Press. 
[12] Jiang, S. Y. (1997). On BA construction and its functional expansion. Studies of the Chinese Language 4, 298-304.

[13] Kit, C. (1998). Ba and bei as multi-valence prepositions in Chinese. In K. T'sou Benjamin (ed.), Studia linguistica sinica. Language Information Sciences Research Centre, City University of Hong Kong, 497-522.

[14] Li, C. (2015). On the v-de construction in mandarin Chinese. Lingua Sinica 1.6, 1-40.

[15] Li, F. Q. (2011). The mapping of composite thematic roles to grammatical functions in mandarin resultative verb compounds. Journal of Foreign Languages 34.6, 19-25.

[16] Li, F. Q. (2012). Mapping of thematic roles and grammatical function in the passive constructions of mandarin resultative verb compounds. Foreign Languages and Literature 28.3, 62-67.

[17] Li, F. Q. (2018). The mapping of thematic roles onto grammatical functions in mandarin $b a$ construction indicating disposal: From the perspective of Lexical Mapping Theory. Language and Translation 3, 42-52.

[18] Li, Y. F. (1995). The thematic hierarchy and causativity. Natural Language and Linguistic Theories 13, 255-282.

[19] Shao, J. M. \& C. L. Zhao. (2005). Cognitive interpretation of ba-construction and bei-construction. Chinese Language Learning 4, 11-18.

[20] Wang, L. (1980). History of the Chinese language. Beijing: Zhonghua Shuju.

[21] Wen, B. L. \& J. Cheng. (2007). On the purely syntactic nature of light verb v. Modern Foreign Languages 30.2, 111-123.

[22] Yang, G. W. (2014). The SFG ergative interpretation on the participants in the bă construction and the bèi construction. Contemporary Linguistics 16.4, 410-421.

[23] Zhang, M. H. \& L. Bai. (2013). A review of the studies of BA constructions in the new era. Journal of China University of Mining \& Technology (Social Sciences) 3, 137-144.

[24] Zhang, Z. G. (1956). General knowledge of Chinese grammar. Shanghai: Xin Zhishi Chubanshe (New Knowledge Press).

[25] Zou, H. M. (2001). Semantic and pragmatical analysis on $B A$ construction with the meaning of cause. Language and Translation 1, 18-20.

Fengqi Li graduated from Nanyang Technological University, Singapore (postgraduate diploma in ELT), Chongqing University, Chongqing, China (MA in linguistics) and Sichuan International Studies University, Chongqing, China (BA in English language and culture). He currently teaches the courses of English-Chinese translation, research methodology, and contrastive study of Chinese and western legal cultures at the College of Foreign Languages in the Southwest University of Political Science and Law. His research interests include Chinese syntax, English-Chinese translation and ELT. 